\title{
Dynamic implication of biomass energy consumption on economic growth in sub- Saharan Africa: evidence from panel data analysis
}

\begin{abstract}
The present article examines the dynamic linkages between biomass energy consumption, capital stock, human capital and economic growth across selected Sub-Saharan African countries based on dynamic heterogeneous panels of a mean group (MG) and pooled mean group (PMG) techniques. The finding based on PMG as the preferred method reveals that biomass energy consumption, capital stock and human capital are statistically significant, which means aforementioned variables have positive significant impact on economic growth in the countries studied. When an alternative panel estimation techniques of panel cointegration, dynamic OLS (DOLS) and fully modified OLS (FMOLS) are applied, the result based on panel cointegration technique reveals that biomass energy consumption, capital stock, human capital and economic growth are cointegrated as null hypothesis of most statistics are rejected at $1 \%$ level of significance. The finding based on FMOLS shows that biomass energy consumption, capital stock and human capital positively influences economic growth at $1 \%$ level and same result is obtained from panel OLS. The result based on DOLS however reveals that biomass energy consumption and capital stock are significant at $1 \%$ on economic growth while human capital is insignificant. Considering its positive effect on economic growth with little or no environmental degradation when compared with fossil fuel uses, consumption of biomass energy is more preferable in these countries therefore is the best option to adopt by the policy makers of Sub-Saharan African countries.
\end{abstract}

Keyword: Biomass energy; Economic growth; Panel cointegration; Capital stock; Human capital; Sub-Saharan Africa 